QIJEI

International

Journal for

Educational

Integrity

\title{
Academic integrity and community ties at a small, religious-affiliated liberal arts college
}

\author{
Michael Bath \\ Concordia College, Minnesota, USA \\ bath@cord.edu \\ Peter Hovde, \\ Concordia College, Minnesota, USA \\ hovde@cord.edu
}

\section{Erik George}

Concordia College, Minnesota, USA

ehgeorge@cord.edu

Kacie Schulz

Concordia College, Minnesota, USA

kholcom@cord.edu

Elise Larson

Concordia College, Minnesota, USA

ellarson@cord.edu

Eirik Brunvatne

Concordia College, Minnesota, USA

ebrunvat@cord.edu

Keywords: academic integrity, religious college, community

\section{Abstract}

While the increased incidence of academic integrity violations in university classrooms has been well documented over the past several decades, inconsistent attention has been given to small liberal arts colleges in terms of both cheating practices and attitudes towards cheating. This study aims to address this disparity by focusing on academic integrity at Concordia College in Moorhead, Minnesota; a small undergraduate institution with a strong church affiliation. We hypothesise that institutional practices and the small-college culture that are unique to smaller colleges like Concordia act to limit the incidence of academic integrity violations. Our case study makes use of data collected from two student surveys - one conducted in 2008, and a follow-up survey conducted in 2010. Variables representing a range of internal and external factors that contribute to cheating were incorporated into a regression model designed to measure the impact of contextual influences that are potentially unique to students at a small, church-affiliated liberal arts college. Given our findings, we conclude that the college would be wise to consider adopting a traditional honour code system.

The International Journal for Educational Integrity is available online at:

http://www.ojs.unisa.edu.au/journals/index.php/IJEI/

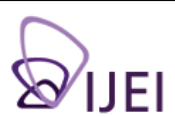




\section{Introduction}

While the increased incidence of academic integrity violations in university classrooms has been well documented over the past several decades (Bowers, 1964; Murphy, 2002; Tibbets, 1998), inconsistent attention has been given to small liberal arts colleges in terms of both cheating practices and attitudes towards cheating. Similarly, a broad body of research focuses on the range of variables that impact academic integrity practices, from age (Lambert, Hogan, \& Barton, 2003; Voert, Felling, \& Peters, 1994) and gender (Wilhelm, 2004) of students, to academic major (Knotts, Lopezz, \& Mesak, 2000), level of extracurricular involvement (Dawkins, 2004; Wilhelm, 2004), and religiosity (Brown \& Choong, 2005; Etter, Cramer, \& Finn, 2006; Faulker \& De Jong, 1968; Rettinger \& Jordan, 2005). While there has been a growth in work that has highlighted the importance of context in determining which of these variables affect academic dishonesty (McCabe \& Trevino, 1993), few studies draw from data sets that reveal the context that is often unique to small, liberal arts colleges with a strong church affiliation. Concordia College in Moorhead, Minnesota, as one such college, serves as a potentially strong test case for the contention that institutional practices and the small-college culture of strong community ties might act to limit the prevalence of academic integrity violations. Our case study makes use of data collected from a student survey conducted in 2008 and then again in 2010. Our findings shed light on both institution-wide and classroom practices that are wellsuited to discouraging academic dishonesty at small, religious-affiliated liberal arts institutions.

\section{The pervasiveness of academic dishonesty}

A number of both longitudinal and cross-sectional studies document the pervasiveness of academic dishonesty on university campuses (Dawkins, 2004). Bowers (1964), in an extensive study of academic integrity practices among postsecondary students, found cheating to be widespread. Subsequent work confirmed these early findings, and indicates that cheating has increased across a range of different practices and demographics (Murphy, 2002; McCabe \& Trevino, 1997). What's clear is that academic dishonesty is now a common experience on campuses nationwide (McCabe, Trevino, \& Butterfield, 2000).

Among the various factors that influence the prevalence of academic dishonesty, a student's gender in particular has been found to have a consistent and strong impact, with males being especially prone to cheating (Dawkins, 2004; McCabe \& Trevino, 1997; Wilhelm, 2004). Although the reasons for the difference in moral reasoning and practices seem to vary, most explanations centre on the belief that females are socialised to be more attuned to ethical issues than are males (Knotts et al., 2000; McCabe \& Trevino, 1997). There is some evidence to suggest that the effect of the gender variable has decreased with time, however, with levels of female cheating increasingly approaching that of their male counterparts (Whitley, 2001).

Similarly, there is consistent and strong support for the effect of peer influence on academic dishonesty (Bowers, 1964; Carrell, Malmstrom, \& West, 2008; McCabe, Butterfield, \& Trevino, 2006; Etter et al., 2006; McCabe et al., 2000; McCabe and Trevino, 1993, 1997). This literature clearly supports the idea that perception of peer cheating drives cheating activity. This is the case among typical undergraduates (McCabe \& Trevino, 1993, 1997), US military service academy students (Carrell et al., 2008), and graduate business school students (McCabe et al., 2006).

Beyond these variables, however, the findings have been somewhat less consistent. When it comes to the effects of age, for instance, Dawkins (2004) finds that younger students are more prone to cheating, since their capacity for moral reasoning and respect for rules and regulations aren't developed to the extent seen with older students. McCabe et al. (2000) also found younger students to cheat more. In 
contrast to these findings, research compiled at two mid-size public universities found the effect of age on moral reasoning in general (Knotts et al., 2000), and academic integrity in particular (Lambert et al., 2003), to be negligible.

Similarly, the impact of a student's course of study varies, depending on the research in question. At a general level, Knotts et al. (2000) found business students to be more attuned to moral integrity and ethical business decisions than their non-business major counterparts, a finding generally supported by lyer and Eastman (2006). Wilhelm (2004), however, found no statistically significant relationship between the academic integrity of business and non-business majors. Klein, Levenburg, McKendall, and Mothersell (2007) also found no difference when looking at business school students compared to students from other professional schools, although business student views on what comprises cheating were actually found to be less stringent. This finding presages a much larger body of literature that finds business students to be among the most dishonest, whether looking at undergraduates or graduate school students (see Bowers, 1964; Caruana, Ramaseshan, \& Ewing, 2000; McCabe et al., 2006; McCabe \& Trevino, 1997). Interestingly, nursing majors were noted to display particularly high levels of moral reasoning, perhaps attributable to the nursing program's strong emphasis on ethical decision-making (Wilhelm, 2004).

Extracurricular involvement, including employment and participation in music ensembles, is often associated with increased academic integrity (Diekhoff, LaBeff, Shinohara, \& Yasukawa, 1999). Involvement in these activities may signify increased responsibility and dedication to academic life, thus helping to explain these students' heightened sense of academic integrity. Conversely, some work argues that being involved takes time away from course work and studying, which makes students more inclined to cheat. This appears to be the case with athletes (McCabe \& Trevino, 1997; Diekhoff et al., 1999) in particular, as well as with members of fraternities and sororities (Lambert et al., 2003; McCabe \& Bowers, 1995). Moreover, even higher rates of cheating are found among those members who are most deeply involved in Greek activities (Storch \& Storch, 2002).

Equally contradictory are the findings on the impact of religiosity. Rettinger and Jordan (2005) note the more devout students are, the less likely they are to cheat, a finding that echoes the work of McNichols and Zimmerer (1985) and Sutton and Huba (1995). The findings of Voert et al. (1994) also confirm the importance of religiosity on moral reasoning. Others contest such findings, however, finding the effect of religiosity on cheating to be inconsistent (Brown \& Choong, 2005; Faulkner \& De Jong, 1968), or non-existent (Michaels \& Miethe, 1989; Smith, Ryan, \& Digging, 1972; Wilhelm, 2004).

\section{The importance of context}

To the extent that there is some degree of inconsistency in the literature on the effects of key variables underscores the importance of context in the study of academic integrity. Differences in methodology (Dawkins, 2004) and the size of institutions studied (McCabe \& Trevino, 1997) undoubtedly affect results. Moreover, institutions with widely divergent characteristics produce different cultures that either enhance or hinder the degree of academic dishonesty that takes place (Pulvers \& Diekhoff, 1999). In short, campus environment, both in and out of the classroom, is important. In the words of Pulvers and Diekhoff (1999, p. 495), students are more likely to cheat if their campus experience is "less personalized, less satisfying, less task oriented, and less individualized". Given this, might institutions that are smaller in size and so able to foster a strong sense of community, belonging, and an ethic of responsibility be better positioned to discourage academic dishonesty? The work of Pulvers and Diekhoff would seem to suggest this indeed is possible. 
This study examines student attitudes and practices regarding academic integrity at Concordia College in Moorhead, Minnesota. The college exhibits several characteristics that make it a good test case for the contention that institutional practices and the small-college culture that are unique to smaller, church-related institutions of higher learning act to limit the prevalence of academic integrity violations. Concordia College is an undergraduate liberal arts college, with a student body of approximately 2,600 students. The college is affiliated with the Evangelical Lutheran Church of America (ELCA). Compared to its sister ELCA institutions, Concordia is known for having maintained an especially strong religious identity (though without being overly doctrinaire). The community ethos that the college often references in its marketing efforts is embodied by an abundance of opportunities for extracurricular activity, the potential for developing close relationships between professors and students, and regular campus worship services. Inside the classroom, discussion as well as lecture is common, classes tend to be modest in size (the student-to-faculty ratio is 13:1), and written exams and assignments are mostly the norm. All students must complete a core curriculum that is designed to encourage lifelong learning and responsible engagement in the world. In short, the 'learning community' the college seeks to foster would seem to conform well to the measures of personalisation, satisfaction, task orientation, and individualisation that Pulvers and Diekhoff (1999) identify as key to minimising academic dishonesty.

\section{Research design}

\section{Questionnaire}

The survey instrument (adapted from Higbee \& Thomas, 2002) measured three dimensions of cheating. First, students were asked which of the 32 items they defined as an act of academic dishonesty (Definition of Cheating), ranging from writing another's paper and plagiarising sources, to stealing library resources and using technology (e.g. calculators and cell phones) to cheat on exams. Second, they were asked to report which of the same practices they perceived others engaging in (Perception of Cheating). Third, students were asked which behaviours they themselves had engaged in (Cheating Self-Report). The remaining questions measured a number of potential explanations for the variation in the three cheating dimensions. These explanatory variables clustered in four groups: educational (academic class, GPA), social relationships (e.g. pressure from parents, having friends who cheat), the honour regime (e.g. being aware of rules, belief that rules are effective), outside activities (e.g. work hours, extracurricular activities), and a single variable, gender.

\section{Sample}

We drew a convenience sample which we designed to be as representative as possible. We selected courses that were mostly part of the liberal arts core in proportion to the relative sizes of the four academic classes. The questionnaire was administered to all students in each course, although students who reported having taken the questionnaire in another class were excused. The sampling produced a total of 512 respondents. Compared to known parameters of the population, a couple of slight biases emerged. First-year students are slightly underrepresented in the sample. The reported GPA of the sample is also somewhat higher than the actual college-wide average GPA. Part of this inflation could be due to the underrepresentation of first-year students, who average a lower GPA than their upper-class counterparts. It also might be true that students tend to claim an inflated GPA, as the measure is something of a status symbol. Or, we simply may have netted students with a higher GPA on average. If this is a real bias, it is difficult to know in which direction the consequences of this bias might run, as one can make a plausible argument in either direction. For gender, the proportions almost exactly mimicked the population parameter. 


\section{Definition and measurement}

Definition: What is cheating?

Students were asked whether or not each behaviour described an instance of cheating. The 32 items empirically grouped themselves into three distinct groups. Consensus prevailed that 22 items described examples of cheating, ranging from using unauthorised notes to cheat on an exam to fabricating a list of references. Consensus was also evident that six items were not cheating, including discussing an exam outside of class and accidentally misquoting a source. However, on five items (e.g. failing to contribute one's fair share to a project, failing to properly cite a reference, etc.), students did not agree whether the behaviour should be considered cheating or not.

We find it difficult to discern either pattern or rationale, across or within the groupings. It appears that students consider the consequences of those items defined as not cheating to be inconsequential or the behaviour inadvertent, while the behaviours defined as cheating are generally of more consequence and intentional.

\section{Behaviour: What have I done?}

The students' reports of their own behaviour do not group themselves quite as obviously as on the other scales. If cut-points are defined using empirical gaps in the distribution of self-reports (the empirical approach), then only three items (all of them class 'veterans' providing assistance to current class members) are reported by nearuniversal proportions of respondents. Below them, a widely dispersed middle category of five items brings other motives and consequences into the mix, just as widely dispersed as the data themselves: the inconsequential ("talking about something else during an exam" at $63 \%$ ), the unintentional ("accidentally misquoting a source" at $62 \%$ ), to the material and the intentional ("getting exam answers from someone else" at $37 \%$ ). On the other hand, using a more 'mathematical' approach to categorising (defining the upper cut-point at $\geq 75 \%$ and the lower at $\leq .25 \%$ ), the middle category would gain five more items, with the bordering three finding students confessing to both sins of omission and commission (not contributing fair share, copying an exam, and lying to obtain an extension). The lower category would find between $23 \%$ and $4 \%$ of students report engaging in behaviour described in just shy of three out of five of the items ("submitting writing from the web" and "hiding library materials" the leastreported behaviours at $5 \%$ and $4 \%$ respectively).

\section{The usual suspects}

While we can discern no clear conceptual definitions emerging from these collections of items on any of these three attempts at categorisation, ten items found on one or more of the 'interesting ends' of the three continua are found on at least one of the ends of interest of another continua, and six of the items are found on all three. That is, these items are found in the definitional categories of disagreement or consensus that the behaviour is not cheating, found in the "everybody's doing it" perception category, and the "confessional" end of the self-reported behaviour category, as seen in Table 1. The greatest overlap is found between the self-report and the perception of others. All but one of the top ten items perceived by others were also found to top two self-report categories (from a total of items). In one sense, students' own behaviour seems to be a mirror of what they perceive others to be doing (or perhaps projecting on others what they themselves are doing). 
Table 1:

The usual suspects

\begin{tabular}{|l|c|c|c|}
\hline Item & Perception & Not defined as & Self-reported \\
\hline & & & \\
\hline Fail to contribute fair share to project & $\sqrt{ }$ & $\sqrt{ }$ & \\
\hline Discussing exam outside class & $\sqrt{ }$ & $\sqrt{ }$ & $\sqrt{ }$ \\
\hline $\begin{array}{l}\text { Helping one study for class you have tak- } \\
\text { en }\end{array}$ & $\sqrt{ }$ & $\sqrt{ }$ & $\sqrt{ }$ \\
\hline Providing assignment as example & $\sqrt{ }$ & & $\sqrt{ }$ \\
\hline $\begin{array}{l}\text { Getting answers from someone ... taken } \\
\text { exam }\end{array}$ & $\sqrt{ }$ & $\sqrt{ }$ & $\sqrt{ }$ \\
\hline Lying to obtain extension & $\sqrt{ }$ & $\sqrt{ }$ & $\sqrt{ }$ \\
\hline Failing to properly cite reference & $\sqrt{ }$ & $\sqrt{ }$ \\
\hline Pasting from internet without quote marks & $\sqrt{ }$ & & $\sqrt{ }$ \\
\hline Talking about something else during exam & $\sqrt{ }$ & & \\
\hline Accidentally misquote source & & & \\
\hline
\end{tabular}

\section{The other-self gap}

However, the gap between students' reports of their own behaviour and their perceptions of others' behaviour invariably finds other students cheating to a greater extent. The average gap is 27 points. The smaller gaps were found on items "helping one study for class you have taken" $(5 \%)$ and "accidentally misquote source" $(6 \%)$. "Fail to contribute fair share to project" showed the greatest gap (73\%), followed by "Iying to obtain extension" (51\%). Of those items exhibiting larger gaps ( $\geq .35 \%)$, nearly all $(78 \%)$ were defined as cheating by consensus, while none were defined as not cheating by consensus. On the other hand, nearly all of the six smaller gap items were defined as not cheating by consensus, with the one remaining item from the disagreement group.

A number of factors seem to be at work in explaining variation in these perceptionbehaviour gaps. Some of the smaller gaps were found on behaviours not easily observed by others. These smaller gaps are not surprising, since nearly all these perceived behaviours were defined as not cheating, as well as engaged in by most of the reporting students themselves. It might be tempting to conclude that the larger gaps reveal that a lot of cheating is going on. However, the data do not indicate whether students' perceptions are based on patterns of behaviour, or single or scattered instances.

\section{The impact of perception}

In short, students as a group are doing what they perceive others to be doing. They (as a group) are just doing less of it. This finding may point to an effective set of strategies to reduce cheating. If students could be convinced that others are cheating less, they might follow suit.

The big exception here is the item that haunts teachers who employ small group projects in our classrooms: getting each student to contribute their fair share to the product. As noted above, while the perception that others are not doing their fair share is universal $(100 \%)$, only $27 \%$ admit to such a failing themselves. If our respondents are reporting honestly, and we suspect they are, then a key to resolution of the "fair share" problem might lie in explicating to students what fair contribution really should look like.

\section{The impact of definition}

What students define as cheating should evidence an inhibiting effect on behaviour. The negative relationship between definitions of cheating and self-reported behaviour in Figure 2 shows this clearly to be the case. Correlating those 13 items on which 
$25 \%$ or more of the respondents report engaging in, with what proportion perceive the item to be cheating (ranging from $5 \%$ to $96 \%$ ) shows a markedly clear trend that increasing agreement that some behaviour is cheating reduces the proportion of students reporting the behaviour. This relationship indicates that one way to reduce the incidence of cheating may be to lead students to believe that items in the disagreement and not cheating categories are in fact cheating.

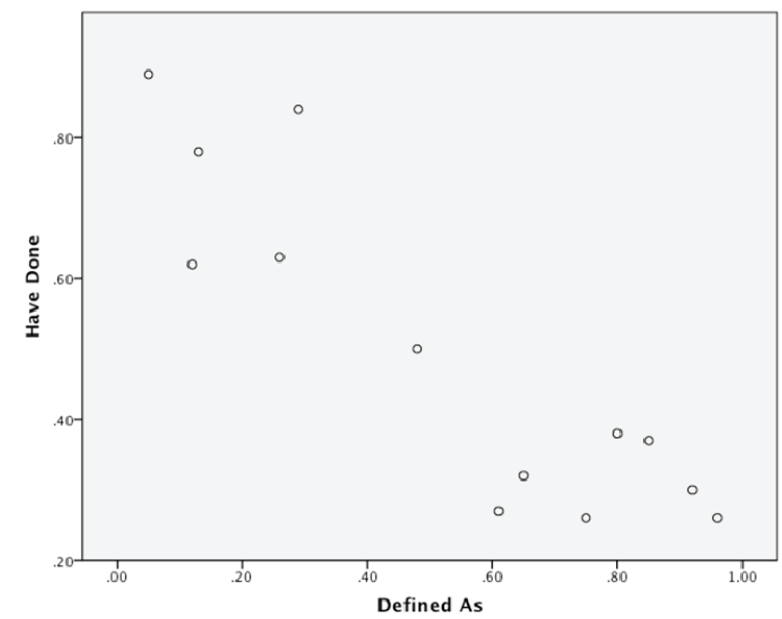

Figure 1. Self-reported behaviour by cheating definition

\section{Scaling the data}

Since the purpose of this paper is to ferret out factors susceptible to policy actions which might reduce the incidence of cheating, the focus of the remaining analyses is on statistically 'explaining' variation in self-reported behaviour. With 32 measures of the dependent variable, some simplification was necessary.

The items of behavioural consensus on either end of the continuum (three "everybody's doing it" and 19 items with fewer than $25 \%$ or less students reporting to have engaged in the behaviour) were eliminated from consideration. We then attempted to scale the remaining ten items. Using Reliability Analysis, the best we could do was a 7-item set of questions which barely scaled at the low end of the social science standard (Cronbach's alpha of .601). Given our earlier inability to discern trends or rationale across our 32 measures, such a scaling result was not surprising. Given that the bias produced by using such a weak scale, if any, is likely to reduce the statistical strength of actual relationships, we decided to proceed to bivariate analysis using the scale.

Table 2:

Items which scaled (Cronbach's alpha $=.601$; Reliability program, PASW)

\begin{tabular}{|l|l|}
\hline$\%$ Self-Report & Scaled Items \\
\hline $62 \%$ & Accidentally misquote source \\
\hline $50 \%$ & Failing to properly cite reference \\
\hline $38 \%$ & Copying few sentences without quote marks \\
\hline $37 \%$ & Getting answers from someone who has taken exam \\
\hline $32 \%$ & Failing to list all sources \\
\hline $30 \%$ & Pasting from internet without quote marks \\
\hline $27 \%$ & Fail to contribute fair share to project \\
\hline
\end{tabular}


The distribution of the self-reported cheating behaviour is shown in Figure 2, with the numbers of the horizontal axis indicating the number of engaged behaviours Respondents in the "no cheating" column reported engaging in none of the behaviours, while those in the "Most cheating" column reported engaging in all seven.

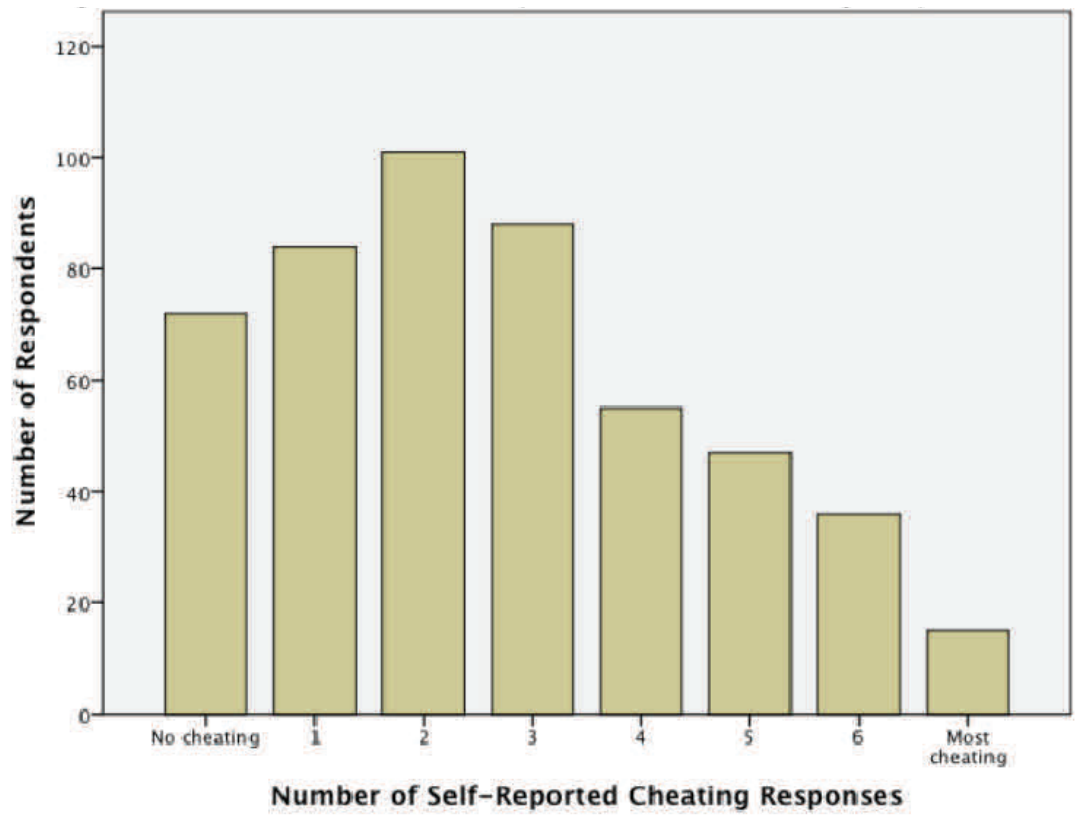

Figure 2. Distribution of self-reported 7-item cheating responses

The search for the explanations of cheating

We were seeking an explanatory model of tendency to cheat which was both powerful (robust adjusted R-squared) and parsimonious (relatively few independent variables). We used bivariate regression analysis to eliminate those variables not statistically significantly related to the cheating scale. Some potentially important variables which did not make the first cut were: required religion courses taken, academic class, feelings of community and fitting in, the deterrence elements of the honour regime such as monitoring and punishment, volunteer work or participation in student organisations, participation in individual sports, and hours of work.

These variables composed an equation submitted to step-wise regression analysis, in which the impact of each independent variable was assessed while simultaneously controlling for all the other variables in the model. Variables which were significant at the bivariate level which disappeared under the statistical controls of the step-wise procedure were: pressure from parents, the efficacy of the honour regime, comfort feelings toward professors, participation in music ensembles and total time spent in extracurricular activities, and gender.

These winnowing processes left us with a set of seven remaining independent variables: friends who cheat, GPA, business major, homework hours, team sports, intramural sports, and awareness of rules and procedures. We compared the beta weights to assess the relative explanatory potency of factors within the model.

Four variables evidenced a substantial explanatory contribution: friends who cheat (Beta=.357), GPA (Beta=-.223), business major (Beta=.153), and homework hours (Beta=-.123), in decreasing order of importance, together explaining $26.8 \%$ of the variance. Team sports, awareness of rules, and intramural sports were either not found to be statistically significant or contributing anything substantial to the explanation (R-square), and were not included in the resulting model. Having friends 
who cheat may legitimise the practice in the minds of students, and those with robust GPAs and more diligent in their study habits do not feel the need to cheat, while the great propensity for business majors to cheat is a common study result (Bowers, 1964; Caruana et al., 2000; McCabe et al., 2006; McCabe \& Trevino, 1997).

That we found Concordia business majors more likely to cheat than the typical student is no surprise. Just why that is true is another question. It is unlikely that our business department is advising students to cut ethical corners - the department sponsors a Center for Business Ethics and Leadership, and is intentional about emphasising ethics throughout the curriculum. It may, however, be that business as a career attracts students who possess less demanding ethical frameworks. Rettinger and Jordan (2005) did find business students to be more grade-oriented in their motivation, as compared to other students who were more learning-oriented. This ethical inexactitude could be reinforced as students are taught the economics of the day where markets are held as sacrosanct. As Michael J. Sandel theorises, if we let markets make most of our choices, our ethical principles whither in disuse (Sandel, 2012). What looks to be clear here is that our Business Department is not fully effective in enhancing the ethical belief systems and behaviours of its majors.

That involvement in sport failed to show significant impact will be disappointing to those who cling to the hoary hope that abiding by the rules of the game imparts life lessons learned. The bivariate results would indicate that if there is any such effect at all, it runs in the opposite direction today, a finding common in the literature (McCabe \& Trevino, 1997; Diekhoff et al., 1999). That "awareness of rules" did not show any significant independent effect actually runs counter to the common understanding (McCabe \& Trevino 1993, 1997), and calls into question the value of the honour regime at Concordia. As discussed below, however, the College's honour system falls far short of what is typically identified to be an effective honour code.

\section{The impact of contextual and other variables}

We then took a contextualist (see Czudnowski, 1976) tack in our analysis by comparing the step-wise results of different subsamples: gender, the time-draining effects of extracurricular activities and work, and academic class.

Almost without exception, having friends who cheat led the list of explanatory factors in each model. The two exceptions were high number of extracurricular hours and upper class students, and in each of those cases, the friends factor was in a strong second place. The second-place factor for females was GPA, while for males it was homework hours. Since both of those factors indicate a motive for academic performance, the difference between women and men is probably insubstantial. Both levels of working hours (low and high) found friends in first place and business major in third. Similarly, for gender, homework and GPA (low and high respectively) were in second place, a difference unlikely to be substantial. For extracurricular hours, both friends and GPA are contributors, while the low hours group finds business major in second place. Again, the differences do not seem great.

It is with the academic class variable that things get really intriguing. With underclass students (first-year and sophomores), one factor crowds out all the others: friends who cheat $(B e t a=.446, R$-square $=19.8 \%)$. On the other hand, juniors and seniors have three factors in play: GPA (Beta $=-.428)$, friends (Beta $=.311)$, and business major (Beta=.190), with an R-square of $33.5 \%$ of the variance explained. It would seem that as graduation approaches, laggard students realise the importance of a higher GPA and are tempted more to cheat.

It is true that a cross-sectional research design such as ours does not offer a strong test of such developmental hypotheses (increasing concern with grades, increased immersion in the business milieu). However, these hypotheses are plausible, and the evidence points in the expected direction. Most intriguing of all, however, is that all 
these factors are actionable, that creative interventions can be employed at both ends of the academic experience to moderate the impact of friends, grades, and major on the propensity to cheat. For that reason, this academic class distinction may well be among the more important of our substantive findings.

\section{Discussion}

The picture that emerges from the data suggests that Concordia's small-college culture (replete with close faculty-student interaction, strong community ethos, and multiple opportunities for social bonding through extracurricular activities) is only partially effective in discouraging academic dishonesty. The impact of Concordia's religion requirement (admittedly a rough measure of religiosity) was insignificant, as were the measures of community (i.e. students' 'fit', perception of community strength, and comfort level with professors). Extracurricular involvement in the form of participation in sports and music programs had insignificant effects on the incidence of cheating, although the broader measure of extracurricular hours had a small and positive impact. Taken together, these findings make Concordia College appear to be largely similar (at least in terms of the effects of its culture on cheating practices) to other sorts of institutions (the larger, and thus more 'impersonal' institutions) from which the college commonly tries to differentiate itself. The small-college culture that is so valued at small church-affiliated institutions like Concordia may enhance campus life in multiple ways, but it would seem that any distinguishing and positive effect on academic integrity practices is largely yet to be realised.

Part of the explanation for this conclusion lies with the findings on friends who cheat. Peer influences are known to be an especially strong correlate of academic dishonesty (Bowers, 1964; Carrell et al., 2008; Etter et al., 2006; McCabe et al., 2006; McCabe et al., 2000; McCabe \& Trevino, 1993, 1997). In Concordia's case, the design of the honour regime is conspicuously lacking in characteristics that might work to effectively encourage a moral calculus among students capable of offsetting the perception that peers regularly engage in unethical academic behaviour. Institutional efforts specific to academic dishonesty largely emphasise expectations and sanctions. This is certainly characteristic of academic integrity practices as articulated in the student handbook, as well as in syllabi (where faculty are required to include their own expectations and penalties for dealing with various sorts of violations). Responsibility for policing and adjudicating breaches in conduct is left mainly in the hands of faculty and administrators (other than a token single-student presence on sanction review panels), disregarding any more meaningful role that could potentially be played by students.

By contrast, much has been made in the literature of the impact of honour codes on academic integrity (McCabe \& Trevino, 1993, 1997, 2002; McCabe, Trevino, \& Butterfield, 2002; Hall \& Kuh, 1998), in particular their ability to create "an environment of trust" (McCabe et al., 2000, p. 224) that mitigates against cheating. Key components of successful codes include requiring students to formally pledge their commitment to honest behaviour, but more critically, ensure that students report academic dishonesty when they encounter it, play a meaningful role in the adjudication of disputes and the leveling of sanctions, and enjoy unproctored exams. The goal of such practices is to foster a sense of communal responsibility for academic honesty, by defining integrity as an institutional priority (McCabe \& Trevino, 2002).

Creating a shared culture proves easier on small campuses, where communal ties tend to be stronger (McCabe \& Trevino, 2002). Given that Concordia already has a strong culture built on religious ties, community values, and service, moving to an honour code system that could work to disrupt peer influences that send the message that 'everybody does it' would likely be easier than on campuses where such strong cultural ties do not exist. In effect, the college would be embracing and extending its 
cultural values in a way that could help to mitigate academic dishonesty. Concordia would do well to consider such a course of action.

We close with a methodological note. Although the seven items which measured the degree of self-reported cheating barely scaled (alpha of .601), the fact is that the analysis using the scale score to measure the dependent variable turned out to be related in significant and expected ways to the independent variables in the model. These results enhance the construct validity of the scale (the measure empirically correlates with other variables in expected ways). Therefore, at least for this population, the number of the questionnaire items employed in future research could be vastly reduced to these seven items only. Other researchers could determine if this strategy is effective for other populations.

\section{References}

Bowers, W. J. (1964). Student dishonesty and its control in college. New York: Bureau of Applied Social Research, Columbia University.

Brown, B. S., \& Choong, P. (2005). An investigation of academic dishonest among business students at public and private United States Universities. International Journal of Management, 22(2), 201-214.

Carrell, S. E., Malmstrom, F. V., \& West, J. E. (2008). Peer effects in academic cheating. The Journal of Human Resources, XLIII(1), 173-207.

Caruana, A., Ramaseshan, B., \& Ewing, M. T. (2000). The effect of anomie on academic dishonesty among university students. International Journal of Educational Management, 14(1), 23-30.

Czudnowski, M. M. (1976). Comparing political behavior. Beverly Hills, CA: Sage.

Dawkins, R. L. (2004). Attributes and statuses of college student associated with classroom cheating on a small-sized campus. College Student Journal, 38(1), 116-129.

Diekhoff, G. M., LaBeff, E. E., Shinohara, K., \& Yasukawa, H. (1999). College cheating in Japan and the United States. Research in Higher Education, 40, 343-353.

Etter, S., Cramer, J. J., \& Finn, S. (2006). Origins of academic dishonesty: Ethical Orientations and personality factors associated with attitudes about cheating with information technology. Journal of Research on Technology in Education, 39(2), 133-155.

Faulkner, J. E., \& De Jong, G. F. (1968). A note on religiosity and moral behavior of a sample of college students. Social Compass, 15(37), 37-44.

Hall, T., \& Kuh, G. (1998). Honor among students: Academic integrity and honor codes at state-assisted universities. Journal of Student Affairs Research and Practice, 36(1), 41-57.

Higbee, J. L., \& P. V. Thomas. (2002). Student and faculty perceptions of behaviors that constitute cheating. NASPA Journal, 4O(1), 39-52.

Iyer, R., \& Eastman, J. K. (2006). Academic dishonesty: Are business students different from other college students? Journal of Education for Business, 82(2), 101-110.

Klein, H. A., Levenburg, N. M., McKendall, M., \& Mothersell, W. (2007). Cheating during the college years: How do business school students compare? Journal of Business Ethics, 72, 197-206

Knotts, T.L., Lopezz, T. B., \& Mesak, H. I. (2000). Ethical judgments of college students: An empirical analysis. Journal of Education for Business, 57(3), 158163.

Lambert, E. G., Hogan, N. L., \& Barton, S. (2003). Collegiate academic dishonesty revisited: What have they done, how often have they done it, who does it, and why did they do it? Electronic Journal of Sociology, 7(4), 1-25. 
McCabe, D. L., \& Bowers, W. J. (1995). The relationship between student cheating and college fraternity or sorority membership. NASPA Journal, 12, 280-290.

McCabe, D. L., Butterfield, K. D., \& Trevino, L. K. (2006). Academic dishonesty in graduate business programs: Prevalence, causes, and proposed action. Academy of Management Learning and Education, 5(3), 294-305.

McCabe, D. L., \& Trevino, L. K. (2002). Honesty and honor codes. Academe, 88(1), 37-41.

McCabe, D. L., \& Trevino, L. K. (1997). Individual and contextual influence on academic dishonesty: A multi-campus investigation. Research in Higher Education, 38, 379-396.

McCabe, D. L., \& Trevino, L. K. (1993). Academic dishonesty: Honor codes and other contextual influences. Journal of Higher Education, 64, 522-538.

McCabe, D. L., Trevino, L. K., \& Butterfield, K. D. (2002). Honor codes and other contextual influences on academic integrity: A replication and extension to modified honor code settings. Research in Higher Education, 43(3), 357-378.

McCabe, D. L., Trevino, L. K., \& Butterfield, K. D. (2000). Cheating in academic institutions: A decade of research. Ethics and Behavior, 11(3), 219-232.

McNichols, C. W., \& Zimmerer, T. W. (1985). Situation ethics: An empirical study of differentiators of student attitudes. Journal of Business Ethics, 4, 175-180.

Michaels, T. W., \& Miethe, T. D. (1989). Applying theories of deviance to academic cheating. Social Science Quarterly, 70, 870-885.

Murphy, J. (2002). Getting away with it. Tiger-Weekly, 205(1), 15A.

Pulvers, K., \& Diekhoff, G. M. (1999). The relationship between academic dishonesty and college classroom environment. Research in Higher Education, 40(4), 487498.

Rettinger, D. A., \& Jordan, A. E. (2005). The relations among religion, motivation, and college cheating: A natural experiment. Ethics and Behavior, 25(2), 107-129.

Sandel, M. J. (2012). What money can't buy: The moral limits of markets. New York: Farrar, Straus, and Giroux.

Smith, C., Ryan, E., \& Digging, D. (1972). Moral decision making: Cheating on examinations. Journal of Personality, 40, 640-660.

Storch, E. A., \& Storch, J. B. (2002). Fraternities, sororities, and academic dishonesty. College Student Journal, 36(2), 247.

Sutton, M., \& Huba, M. (1995). Undergraduate student perception of academic dishonesty as a function of ethicity and religious participation. NASPA Journal, 33, 19-34.

Tibbets, S. G. (1998). Differences between criminal justice majors and non-criminal justice majors in determinants of test cheating intentions: A research note. Journal of Criminal Justice Education, 9, 81-94.

Voert, M., Felling, A., \& Peters, J. (1994). The effect on self-interest morality. Review of Religious Research, 35(4), 302-323.

Whitley, B. E. (2001). Gender differences in affective responses to having cheated: The mediating role of attitudes. Ethics and Behavior, 11, 249-259.

Wilhelm, J. W. (2004). Determinants of moral reasoning: Academic factors, gender, richness-of-life experiences, and religious preferences. Delta Pi Epsilon Journal, 46(2), 105-123.

\section{About the authors}

Michael Bath, $\mathrm{PhD}$ is Professor and Chair of the Political Science Department at Concordia College in Moorhead, Minnesota. His teaching and research interests encompass a range of topics in American politics, most notably think tanks and clean election reforms. 
Peter Hovde, PhD is a Professor of Political Science at Concordia College. He served as Concordia's Director of International Education for over two decades. His teaching and research interests span environmental action (particularly in the Arctic region) as well as developments in study abroad and other types of global education initiatives.

Erik George, Kacie Schulz, Elise Larson, and Eirik Brunvatne were Concordia College undergraduates at the time the survey data was collected and analysed. Erik now works as a Leadership Fellow with the Port Authority of New York and New Jersey. Kacie is a client relations specialist at Merrill Lynch in Fargo, North Dakota. Elise is an attorney with Briggs and Morgan in Minneapolis, Minnesota. Eirik currently serves as an environmental advisor at Statkraft in Oslo, Norway. 